\title{
Effects of study design and trends for EVAR versus OSR
}

\author{
Robert Hopkins' \\ James Bowen' \\ Kaitryn Campbell' \\ Gord Blackhouse ${ }^{4}$ \\ Guy De Rose ${ }^{2,3}$ \\ Teresa Novick ${ }^{2}$ \\ Daria O'Reilly',4 \\ Ron Goeree ${ }^{1,4}$ \\ Jean-Eric Tarride ${ }^{1,4}$ \\ 'Programs for the Assessment \\ of Technology in Health (PATH) \\ Research Institute, \\ Department of Clinical Epidemiology \\ and Biostatistics; ${ }^{2}$ Division \\ of Vascular Surgery, Department \\ of Surgery, London Health Sciences \\ Center, London, Ontario, Canada; \\ ${ }^{3}$ Division of Vascular Surgery, \\ Department of Surgery, Faculty \\ of Medicine, University of Western \\ Ontario, London, Ontario, Canada; \\ ${ }^{4}$ Department of Clinical Epidemiology \\ and Biostatistics, Faculty of Health \\ Sciences, McMaster University, \\ Hamilton, Ontario, Canada
}

Purpose: To investigate if study design factors such as randomization, multi-center versus single center evidence, institutional surgical volume, and patient selection affect the outcomes for endovascular repair (EVAR) versus open surgical repair (OSR). Finally, we investigate trends over time in EVAR versus OSR outcomes.

Methods: Search strategies for comparative studies were performed individually for: OVID's MEDLINE, EMBASE, CINAHL, HAPI, and Evidence Based Medicine (EBM) Reviews (including Cochrane DSR, ACP Journal Club, DARE and CCTR), limited to 1990 and November 2006.

Results: Identified literature: 84 comparative studies pertaining to 57,645 patients. These include 4 randomized controlled trials (RCTs), plus 2 RCTs with long-term follow-up. The other 78 comparative studies were nonrandomized with 75 reporting perioperative outcomes, of which 16 were multi-center, and 59 single-center studies. Of the single-center studies 31 were low-volume and 28 were high-volume centers. In addition, 5 studies had all patients anatomically eligible for EVAR, and 8 studies included high-risk patients only. Finally, 25 long term observational studies reported outcomes up to 3 years.

Outcomes: Lower perioperative mortality and rates of complications for EVAR versus OSR varied across study designs and patient populations. EVAR adverse outcomes have decreased in recent times.

Conclusion: EVAR highlights the problem of performing meta-analysis when the experience evolves over time.

Keywords: abdominal aortic aneurysm, endovascular repair, open surgical repair, systematic review, meta-analysis

\section{Introduction}

Two recent reviews have described the relative outcomes of endovascular repair (EVAR) versus open surgical repair (OSR) (Drury et al 2005; Ho et al 2006) and of EVAR alone (Franks et al 2007) for abdominal aortic aneurysms (AAA) based on evidence from both randomized control trials (RCTs) and nonrandomized control trials (nRCTs). Despite these recent reviews, there are limitations in the accumulated evidence for an assessment comparing EVAR and OSR. As the authors suggest, the major differences between the RCTs and the nRCTs relate to differences in baseline characteristics of the patient populations and overall study design. While the recent reviews have cautioned the interpretation of the differential outcomes of EVAR versus OSR found in RCT compared to nRCTs, they do not assess the degree to which the imbalances or different study design impact relative outcomes.

For example, patients in RCTs tend to have lower ASA risk levels than patients in nRCTs, and the average ASA risk tends to be higher for EVAR than OSR patients in nRCTs (Sbarigia et al 2005). This baseline imbalance for AAA repair has continued ever since EVAR was first introduced to benefit patients with AAA who were physiologically at high risk for OSR or who were anatomically suitable for EVAR (Parodi et al 1991). Despite the focus on high risk patients, the benefits of EVAR in 
lower risk patients has also recently been established in two large RCTs, DREAM (Prinssen et al 2004) and EVAR-1 (Greenhalgh et al 2004). Despite these two landmark trials, only one small RCT has been completed to assess differences in quality of life between EVAR and OSR patients (Soulez et al 2005). In order to compare and contrast the outcome evidence of EVAR and OSR in RCTs and nRCTs, differences in patient baseline risk levels and the degree to which these risk levels differ between EVAR and OSR in observational studies need to be investigated.

A major limitation of the recent reviews is the inclusion of studies that should have otherwise been excluded. For example, some studies are multi-center in nature and the meta-analysis includes the results of the multi-center studies and the redundant constituent single center evidence (Brewster et al 1998; Sicard et al 2001; Makaroun et al 2002; Matsumura et al 2003). This is particularly evident with the large device trials, the Lifeline Registry (LREAR 2001) and the Eurostar Registry (Buth and Parodi 1999). In addition, other evidence that should be excluded is the studies that include early evidence from the Ancure multicenter trial, even though the device was temporarily removed from the market for underreporting complications (Moore et al 2001).

Interestingly, EVAR was originally intended for high risk patients, but there has been little cumulative evidence reported for high risk patients only (Sbarigia et al 2005). To address the benefits to high risk patients only, a review of studies where both EVAR and OSR patients are deemed at high medical risk should be the starting point. Similarly, EVAR is usually offered to anatomically suitable candidates. Yet, no review has isolated studies where both EVAR and OSR patients are anatomically suitable for EVAR. To include anatomically suitable patients for a comparative review would eliminate a significant bias in terms of the effects of vasculature on surgical outcomes (Welborn et al 2005).

A further bias is added in reviews if the authors do not incorporate inclusion criterion based on treatment volumes or control for treatment volume in the analysis. This is important because most centers have low annual volume and treatment volumes have been shown to be related to treatment outcomes for endovascular repair (Bush et al 2006) as well as other cardiac procedures (Franks et al 2007). Accordingly, it is important to compare relative outcomes for EVAR and OSR adjusting for different treatment volumes.

Finally, EVAR technology has been evolving over time due to new device generations and improvements in surgical techniques such as crossover grafts (Moise et al 2006).
The recent review of EVAR alone studies described a decreasing rate of mortality over time (Franks et al 2007). Reviews that ignore the potential impact of time trends on the relative rate of mortality or systemic events of EVAR over time may potentially introduce bias.

The objectives of this systematic literature review were to address issues left unanswered by earlier reviews, such as: 1) to describe and compare the patient characteristics from the identified observational and randomized controlled trials of EVAR and OSR patients; 2) to examine differences in outcome measures between the treatment groups by study design and characteristics; and 3 ) to evaluate relative trends in mortality and endoleak rates over time. More specifically, this report investigated the effects of baseline characteristics imbalance, study design (ie, nRCT versus RCT), center status (ie, multi-center versus single center), patient risk status, EVAR suitability, treatment volume (ie, low versus high), and year of study publication on patient outcomes.

\section{Methods}

\section{Literature search}

Literature search strategies were developed to identify papers comparing EVAR to OSR. Strategies for each of the following databases were developed and performed individually in OVID's: MEDLINE, EMBASE, Cumulative Index to Nursing and Allied Health Literature (CINAHL), Health and Psychosocial Instruments (HAPI), and Evidence-Based Medicine (EBM) Reviews (including Cochrane Database of Systematic Reviews (CDSR), ACP Journal Club, Database of Abstracts of Reviews of Effects (DARE) and Cochrane Central Register of Controlled Trials (CCTR)). Results were limited to human and English language studies published between 1990 and November 2006 inclusive. Identification of duplicate citations was completed using Reference Manager (v.10; Thomson ResearchSoft, Philadelphia, PA, USA). RCTs, controlled clinical trials, comparative observational studies, case series studies, and population-based registries assessing the efficacy and/or safety of EVAR versus OSR were all included in the review.

Titles and abstracts (when available) of all search results were screened using predefined criteria in order to identify publications that discussed the use of EVAR and OSR for the management of AAA. When it could not be determined from the information available whether an item met the inclusion criteria or not, the article was reviewed in full-text.

Inclusion criteria included nonruptured AAA repair, of at least a mean AAA diameter of greater than $5 \mathrm{~cm}$, and a publication date from 1990 onwards. Citations were excluded 
if they reported a mixed patient population including patients with thoracic-abdominal aneurysms, iliac aneurysms, ruptured or infected aorta, emergency aortic repair. No restriction based on clinical study design was used and nonrandomized trials and patient registries were included. All relevant or potentially relevant studies were then retrieved in full-text.

Review of full-text articles was conducted to identify publications with unique patient data using preset criteria. Also, clinical studies regarding the FDA-approved clinical trials related to the Ancure device (Guidant) were identified and excluded from further analysis due to the potential underreporting of device related complications (Bren 2003).

\section{Data extraction}

For unique comparative clinical studies, data were abstracted using a standard form to record details of the study design and methods, patient baseline characteristics, technical aspects of EVAR and OSR and outcome measures of interest according to SVS reporting standards (Chaikof et al 2002).

Clinical outcomes were obtained from studies which described 30 day and post 30 day events. When longer term cumulative evidence was available ( $>30$ days), 30 day events were not included in the analysis of the long term outcome data. Studies were classified as multi-center or single center. Where studies examined outcomes from a single center over a period of time greater than one year, annual treatment volume was estimated by dividing the number of patients in the study by the enrollment duration in years. Further, after determining the median surgical volume of institutions performing EVAR, surgical volume was divided into two categories: low volume institutions (identified as having, on average, less than 30 patients per year) and high volume institutions (completed 30 or more procedures per year).

Studies including only high-risk surgical patients were also identified. High-risk patients were classified as highrisk if any one of the following characteristics was present: age $>80$, ASA III or IV, or an existing systemic complication (cardiac, pulmonary, renal) (Hollier et al 1992) If available, further information was extracted from the studies regarding the suitability of patients who received OSR as to whether they could have received EVAR.

\section{Statistical analysis}

Statistical analysis was carried out using Excel 2002 (Microsoft Corp., Redmond, WA, USA) and Stata (StataCorp., College Station, TX, USA) with comparison of dichotomous outcomes expressed as odds ratios (OR). An OR less than 1 indicated a lower rate in EVAR than OSR. Continuous variables were analyzed using weighted mean differences (WMD). A WMD less than zero indicated a lower rate in EVAR than OSR. A level of significance $(\alpha)$ of 0.05 was used to indicate statistical significance.

Meta-regression analyses (including a random effect) were performed using Stata metareg command to test if there were differences in outcomes between EVAR and OSR with respect to study enrolment time. Where there were multi-year enrolment periods, the middle of the time period was used as the independent variable. Trends in comparative outcomes which were analyzed and included were operative mortality, systemic and vascular complications, and adjuvant procedures. Trends in EVAR specific outcomes such as the rate of endoleaks (I-IV) and conversion were also investigated. A level of significance $(\alpha)$ of 0.05 was used to indicate statistical significance in the trend coefficient.

\section{Results \\ Literature search}

The literature search initially completed on 20 May 2005 and updated on 28 Nov 2006 identified a combined total of 3,946 unique citations (see Figure 1). The following evaluation is based on 84 comparative studies, containing unique patient data comparing EVAR to OSR.

\section{Study characteristics}

These 84 studies included 4 randomized controlled trials of which all 4 reported short-term outcomes (Cuypers et al 2001; Greenhalgh et al 2004; Prinssen et al 2004; Soulez et al 2005) and 2 reported subsequent long-term outcomes (Blankensteijn et al 2005; Greenhalgh 2005). The other 78 comparative studies were observational evaluations (nRCT) (3 long term only) (Birch et al 2000; Kibbe et al 2003; LREAR 2005).

Overall, the identified studies contained data pertaining to 59,188 patients. In the 75 observational studies with perioperative outcomes reported (initial 30 days), there were 16,407 and 41,238 patients receiving EVAR and OSR, respectively. Of these observational studies, 16 were categorized as multi-center (Zarins et al 1999; Beebe et al 2001; Criado et al 2003; Matsumura et al 2003; Akkersdijk et al 2004; Anderson et al 2004; Carpenter and Endologix 2004; Greenberg et al 2004; Forbes et al 2005; Hua et al 2005; Leon et al 2005; LREAR 2005; Bush et al 2006; Mendonca et al 2005; Sandridge et al 2006; Wald et al 2006). The other 59 papers were single center evaluations subdivided based on annual surgical volume of 30 cases per year, identified 31 low volume centers (de Virgilio et al 1999; Kahn et al 1999; Seiwert et al 1999; Treharne et al 1999; 


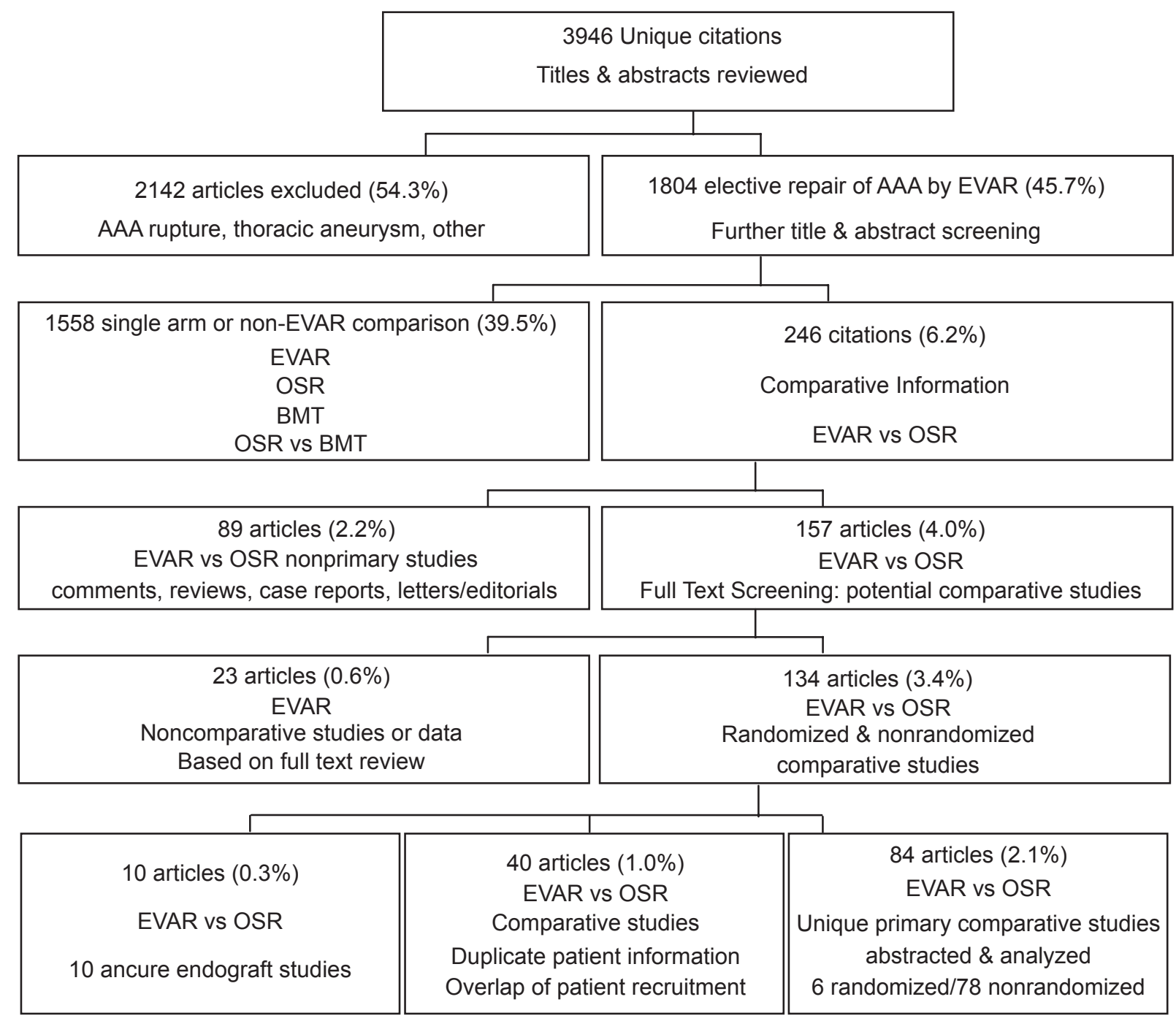

Figure I QUORUM diagram.

Becquemin et al 2000; Cohnert et al 2000; Malina et al 2000; Sangiorgi et al 2001; Berman et al 2002; Davies et al 2002; Forbes et al 2002; Ligush et al 2002; Van Sambeek et al 2002; Gawenda et al 2003; Hansman et al 2003; Patel et al 2003; Ting et al 2003; Turnipseed et al 2003; Ballard et al 2004; Garcia-Madrid et al 2004; Zeebregts et al 2004; Aarts et al 2005; Borchard et al 2005; Goueffic et al 2005; Hayter et al 2005; Iannelli et al 2005; Rosenberg et al 2005; de Donato et al 2006; Manis et al 2006; Vogel et al 2005; Parmer et al 2006), and 28 high volume centers (Baxendale et al 1996; Du Toit et al 1998; Ceelen et al 1999; Scharrer-Pamler et al 1999; Clair et al 2000; Galle et al 2000; Odegard et al 2000; Bertrand et al 2001; May et al 2001; Rowlands and Homer-Vanniasinkam 2001; Wijnen et al 2001; Carpenter et al 2002; Teufelsbauer et al 2002; Arko et al 2003; Decker et al 2003; Dias et al 2003; Dryjskiet al2003; Jordan et al 2003; Junnarkaret al2003;
Aho et al 2004; Angle et al 2004; Cao et al 2004; Elkouri et al 2004; Prault et al 2004; Watson et al 2004; Mehta et al 2005; Englberger et al 2006; Park et al 2006).

Five studies included information regarding patients that were surgically suitable for either procedure (Becquemin et al 2000; Forbes et al 2002; Dias et al 2003; Gawenda et al 2003; Garcia-Madrid et al 2004), 8 studies specifically examined the efficacy of high-risk patients only (Du Toit et al 1998; Carpenter et al 2002; Forbes et al 2002; Patel et al 2003; Iannelli et al 2005; Mendonca et al 2005; de Donato et al 2006; Parmer et al 2006) Long-term outcomes (>30 days) were reported in 25 observational studies with long term comparative outcomes of up to 3 years mean follow- up (Zarins et al 1999; Becquemin et al 2000; Birch et al 2000; Cohnert et al 2000; Beebe et al 2001; May et al 2001; Sangiorgi et al 2001; Carpenter et al 2002; Arko et al 2003; Criado et al 2003; Dias et al 2003; Kibbe and 
Matsumura 2003; Ting et al 2003; Ballard et al 2004; Cao et al 2004; Elkouri et al 2004; Garcia-Madrid et al 2004; Greenberg et al 2004; Zeebregts et al 2004; Goueffic et al 2005; LREAR 2005; Mendonca et al 2005; Bush et al 2006; Carpenter 2006; Parmer et al 2006).

Differences between the EVAR and OSR treatment groups for various baseline characteristics and estimates of short-term mortality, systemic complications, procedural outcomes, local/vascular complications, and EVAR specific outcomes are described below.

Differences between patient characteristics and relative outcomes are discussed in the following order: RCTs versus observational studies, multi-center versus single center observational studies, studies that have patients that are suitable for both procedures (EVAR and OSR), studies with only high risk patients, and finally high volume versus low volume single center evidence.

\section{Patient characteristics RCT vs observational studies}

As shown in Table 1, patients enrolled in the EVAR and OSR arms of the 4 RCTs identified in this review had similar baseline characteristics except for pulmonary history $(\mathrm{OR}=1.81, \mathrm{P}<0.05)$. In contrast, in nonrandomized studies, patients receiving EVAR were more likely to be male (OR 1.64), have higher ASA III and IV ratings (OR 1.33, 1.49 , respectively), and less likely to be ASA I or II (OR $0.20,0.72)$. In all observational studies, EVAR patients had a higher surgical risk with greater baseline comorbidities than in OSR patients.

\section{Multi-center vs single center observational studies}

In single or multi-center institutions, patients receiving EVAR were more likely than patients receiving OSR to have comorbidities such as smoking history, diabetes, hyperlipidemia, cardiac disease, and peripheral vascular disease (PVD) and less likely to have hypertension (Table 1). No statistical difference existed for AAA diameter and age for multi-center or single center evidence. Within the single center evidence, more patients had higher level of ASA in EVAR than OSR (ASA I to IV: OR $0.20,0.72,1.33,2.38$ ). In patients that received EVAR, there were more males, a greater number of individuals with a smoking history, more patients with diabetes, cardiac disease, peripheral vascular disease, and less hypertension. Multi-center evidence included less patients receiving EVAR that have cardiovascular disease, pulmonary, or renal disease, while single center evidence reported the opposite. Fewer patients had stroke in EVAR in multi-center studies, and more had hyperlipidemia in EVAR in single center studies.

\section{Studies with patients anatomically suitable for both EVAR and OSR}

Only 5 studies stated that both EVAR and OSR patients were anatomically suitable for EVAR. While no statistical differences were found between AAA diameter and age, there was a much higher rate of ASA III and IV (OR 2.93, 12.34, respectively) in the EVAR patients than in the OSR patients as compared to the other study designs.

\section{Studies with only high risk patients}

When examining the baseline characteristics of the 8 studies that had high risk patients only, there were no statistical baseline difference in AAA diameter and age. As observed with EVAR studies reporting patient suitability, there were statistically significantly more ASA IV patients that received EVAR than in all nRCTs (OR 10.80).

\section{High volume vs. low volume centers}

The differences in baseline characteristics between the EVAR and OSR patients were still apparent when the single center studies are stratified based on their estimated procedural volume (Table 1). In institutions with high volume, patients receiving EVAR were also more likely than patients receiving OSR to have comorbidities such as smoking history, diabetes, hyperlipidemia, cardiac disease, and peripheral vascular disease (PVD) and less likely to have hypertension (Table 1).

\section{Comparison of perioperative mortality and complications}

RCT vs. observational studies

In the $75 \mathrm{nRCT}$ studies, lower 30-day mortality existed in EVAR than OSR. The mortality difference reported in the nRCTs and in the RCTs was OR $=0.429$ and 0.336 , respectively (Table 2). Of all of the possible study designs and patient populations, RCTs reported the lowest OR for mortality (0.336). Within the published RCTs, there were no statistical differences between EVAR and OSR with respect to the occurrence of a MI, CHF, or arrhythmia, however, not all clinical outcomes were reported in the published papers (Table 2). In all designs lower rates of systemic complications were reported for all measures in EVAR treated patients compared to the OSR group, with the exception of limb ischemia which was higher in EVAR (OR 1.866). 
Table I Difference in patient characteristics by study design and risk status

\begin{tabular}{|c|c|c|c|c|c|c|c|c|}
\hline & $\mathbf{R C T}$ & $\mathrm{nRCT}$ & Multi-center & Single center & Low volume & High volume & Suitable & High risk \\
\hline Studies & 4 & 75 & 16 & 59 & 31 & 28 & 5 & 8 \\
\hline \# EVAR patients & 791 & 16,407 & 12,036 & 4,371 & 1,496 & 2,875 & 260 & 332 \\
\hline \multirow[t]{2}{*}{ \# OSR patients } & 752 & 41,238 & 36,443 & 4,795 & $\mathrm{I}, 752$ & 3,043 & 235 & 352 \\
\hline & WMD. & WMD. & WMD. & WMD. & WMD. & WMD. & WMD. & WMD. \\
\hline Age & -0.43 & -2.02 & -2.27 & -1.49 & -2.03 & -1.01 & -1.17 & -2.84 \\
\hline \multirow[t]{2}{*}{ AAA diameter $(\mathrm{cm})$} & -0.04 & 0.27 & 0.15 & 0.36 & 0.24 & 0.54 & -0.02 & 0.16 \\
\hline & Odds Ratio & Odds Ratio & Odds Ratio & Odds Ratio & Odds Ratio & Odds Ratio & Odds Ratio & Odds Ratio \\
\hline Male \% & 1.13 & $1.64 *$ & $1.76 *$ & $1.44 *$ & $1.19 *$ & $1.62 *$ & 1.23 & $1.66 *$ \\
\hline ASA I & 0.82 & $0.20 *$ & n.a. & $0.20 *$ & $0.21 *$ & n.a. & n.a. & n.a. \\
\hline ASA ॥ & 1.21 & $0.72 *$ & n.a. & $0.72 *$ & $0.52 *$ & 1.19 & $0.09 *$ & n.a. \\
\hline ASA III & 1.14 & $1.33 *$ & 1.01 & $1.33 *$ & 1.06 & $1.53 *$ & $2.93 *$ & $0.39 *$ \\
\hline ASA IV & n.a. & $1.49 *$ & 1.04 & $2.38 *$ & $3.87 *$ & $2.13 *$ & $12.34 *$ & $10.80 *$ \\
\hline Smoking history & 1.17 & $1.19 *$ & $1.20 *$ & $1.22 *$ & $0.83 *$ & $1.57 *$ & $\mathrm{I} .8 \mathrm{I}^{*}$ & $0.37 *$ \\
\hline Hypertension & 1.05 & $0.93 *$ & $0.92 *$ & $0.85 *$ & $0.83 *$ & $0.86 *$ & $1.66 *$ & 0.97 \\
\hline Diabetes & 0.79 & $1.28 *$ & $1.22 *$ & $1.42 *$ & 1.18 & $1.58 *$ & 1.15 & 1.74 \\
\hline Hyperlipidemia & 0.93 & $1.22 *$ & 0.97 & $1.61 *$ & $1.29 *$ & $1.80 *$ & $2.14 *$ & n.a. \\
\hline Cardiac Disease & 0.95 & $1.84 *$ & $2.25 *$ & $1.38^{*}$ & 1.13 & $1.56 *$ & $1.39 *$ & $1.39 *$ \\
\hline CVD & n.a. & 0.89 & $0.68 *$ & $1.28 *$ & 0.98 & $1.38 *$ & n.a. & n.a. \\
\hline Pulmonary & $\mathrm{I} .8 \mathrm{I} *$ & 1.01 & $0.87 *$ & $1.43 *$ & $1.64 *$ & $1.34 *$ & $1.58 *$ & 1.19 \\
\hline PVD & n.a. & $1.28 *$ & $1.21 *$ & $1.39 *$ & 0.77 & $2.33 *$ & n.a. & 1.25 \\
\hline Renal & 0.77 & 0.97 & $0.79 *$ & $1.27 *$ & 1.13 & $1.3 I^{*}$ & 0.72 & 1.15 \\
\hline Stroke & n.a. & 0.48 & $0.20 *$ & 0.92 & n.a. & 0.72 & n.a. & n.a. \\
\hline
\end{tabular}

Notes: *statistically significant: p-value $<0.05$. Both WMD and Odds Ratio were calculated with patient weights.

Abbreviations: n.a., not available;WMD, weighted mean difference; EVAR-OSR, Odds Ratio (EVAR/OSR).

\section{Multi-center vs single center} observational studies

Similar mortality results existed in multi-center versus single center evidence. In addition, the OR of all complications for both multi-center and single center studies were less than 1, indicating the benefit of EVAR vs OSR, in terms of all systemic complications (cardiac, pulmonary, renal, stroke, and ischemia). In general, the multi-center studies reported lower OR for EVAR vs OSR for cardiac and renal complications, similar OR for pulmonary complications. The evidence for stroke and ischemia was mixed.

Studies with patients anatomically suitable for both EVAR and OSR

No statistical difference between EVAR and OSR existed in mortality in anatomically suitable patients. This is important considering that the difference between EVAR and OSR baseline characteristics was the highest in this patient population. There was insufficient evidence to compare systemic complications.

\section{Studies with only high risk patients}

No statistical difference existed in mortality in high-risk patients, despite ASA IV patients being 10.80 times more likely to receive EVAR than OSR. Similarly, there were less complications in EVAR than OSR for cardiac (OR 0.076) and pulmonary complications (OR 0.075) (Table 2).

\section{High volume vs. low volume centers}

Similar differences in mortality existed in high volume versus low volume centers, when compared to all observational studies. In addition, there appeared to be little difference in systemic complications between high volume and low volume centers. This is despite high volume centers having a higher level of ASA IV patients, while low volume centers reported higher levels of other comomorbidities with the exception of pulmonary disease.

\section{Surgical outcomes and local/vascular complications}

Across all types of studies, and treatment volume risk status, surgical outcomes were better for EVAR in terms of OR time, 
Table 2 Mortality and systemic complications

\begin{tabular}{|c|c|c|c|c|c|c|c|c|}
\hline & RCT & $\mathrm{nRCT}$ & Multi-center & Single center & Low volume & High volume & Suitable & High risk \\
\hline & Odds ratio & Odds ratio & Odds ratio & Odds ratio & Odds ratio & Odds ratio & Odds ratio & Odds ratio \\
\hline Studies & 4 & 75 & 16 & 59 & 31 & 28 & 5 & 8 \\
\hline Mortality & $0.336 *$ & $0.429 *$ & $0.437 *$ & $0.539 *$ & $0.508 *$ & $0.555 *$ & 0.797 & 0.517 \\
\hline \multicolumn{9}{|l|}{ Cardiac } \\
\hline Myocardial infarction & 0.655 & $0.401 *$ & $0.250 *$ & $0.463 *$ & 0.178 & $0.486 *$ & - & - \\
\hline Congestive heart failure & 0.159 & $0.55 I^{*}$ & - & 0.622 & - & 0.736 & - & - \\
\hline Arryhthmia & - & $0.198 *$ & 0.391 & 0.216 & $0.107 *$ & $0.262 *$ & - & - \\
\hline Angina & - & $0.047 *$ & - & $0.05 I^{*}$ & - & - & - & - \\
\hline Unspecified & 0.752 & $0.473 *$ & $0.383 *$ & $0.661 *$ & 0.759 & $0.506 *$ & 0.611 & $0.076 *$ \\
\hline \multicolumn{9}{|l|}{ Pulmonary } \\
\hline Failure & - & $0.268 *$ & $0.226 *$ & $0.263 *$ & $0.267 *$ & $0.268 *$ & - & - \\
\hline Edema & - & 0.375 & - & 1.233 & - & & - & - \\
\hline Pneumonia & - & $0.201 *$ & $0.242 *$ & $0.164 *$ & 0.270 & $0.160 *$ & - & 0.306 \\
\hline Pulmonary embolism & - & $0.127 *$ & 0.657 & $0.050 *$ & - & $0.057^{*}$ & - & - \\
\hline Unspecified & - & $0.219 *$ & $0.204 *$ & $0.255^{*}$ & $0.219 *$ & $0.282 *$ & $0.105 *$ & $0.075 *$ \\
\hline Major & $0.246 *$ & $0.288 *$ & $0.427 *$ & $0.126 *$ & - & $0.168 *$ & - & - \\
\hline Moderate & $0.265 *$ & - & - & - & - & - & - & - \\
\hline \multicolumn{9}{|l|}{ Renal } \\
\hline Permanent failure & - & $0.290 *$ & $0.102 *$ & 0.634 & 0.000 & $3.098 *$ & - & - \\
\hline Temporary failure & 1.018 & $0.553 *$ & $0.258 *$ & 0.717 & 0.479 & 0.859 & - & 0.322 \\
\hline Unspecified & - & $0.396 *$ & $0.391 *$ & $0.422 *$ & 0.593 & $0.368 *$ & 0.483 & 0.314 \\
\hline \multicolumn{9}{|l|}{ Stroke and ischemia } \\
\hline Stroke & - & 0.476 & $0.196 *$ & 0.916 & - & 0.715 & - & - \\
\hline $\begin{array}{l}\text { Transient ischemia } \\
\text { Attacks }\end{array}$ & $0.321 *$ & - & - & - & - & - & - & - \\
\hline Bowel/colon ischemia & 2.047 & $0.302 *$ & 0.197 & $0.328 *$ & $0.87 I$ & $0.238 *$ & - & - \\
\hline Limb ischemia & - & $1.866 *$ & - & $2.134 *$ & 2.711 & $2.032 *$ & - & - \\
\hline Spinal ischemia & 0.506 & - & - & 0 & - & - & - & - \\
\hline Other ischemia & - & 0.511 & - & 0 & - & - & - & 0.822 \\
\hline
\end{tabular}

Notes: *statistically significant: $\mathrm{p}$-value $<0.05$. - : not available,

WMD (weighted mean difference) (EVAR-OSR). Odds ratio (EVAR/OSR). Both WMD and odds ratio were calculated with patient weights.

blood loss, ICU length of stay (LOS), and total hospital, but these differences were not always statistically significant (Table 3,4).

\section{EVAR-specific outcomes}

A meta-analysis of the studies reporting endoleak data is presented in Table 5.

\section{Endoleaks}

The rate of type 1 endoleaks was similar across study designs and patient populations, but was absent in the RCTs and highest in the suitable patient group. In contrast, the rate of type 2 endoleaks was lowest in the suitable patient group and in the RCTs.Type 3 and type 4 endoleaks, conversion, graft kinks, or folds are rare.
The rate of graft obstruction is high in the suitable patient group, and the rate of graft migration was highest in the high risk group.

\section{Trends in endoleaks and ischemia over time}

Examining the reported rate against the mid recruitment time of the study demonstrates that Type 1 endoleaks have been decreasing over time (Table 6). In comparison, the rate of type 2 endoleaks is relatively constant. Based on the study reports there has been a statistical increase in the rate of type 3 endoleaks over time (but this is the result of one outlier), and a decrease in the rate of type 4 endoleaks. Finally, the difference in the rate of limb ischemia has been decreasing over time $(\mathrm{P}<0.01)$. 
Table 3 Surgical outcomes

\begin{tabular}{|c|c|c|c|c|c|c|c|c|}
\hline & RCT & $\mathrm{nRCT}$ & Multi-center & Single center & Low volume & High volume & Suitable & High risk \\
\hline & WMD & WMD & WMD & WMD & WMD & WMD & WMD & WMD \\
\hline Studies & 4 & 75 & 16 & 59 & 31 & 28 & 5 & 8 \\
\hline Operating time (hours) & $-0.30 *$ & -0.85 & $-1.03 *$ & -0.80 & -0.40 & $-1.08 *$ & -2.70 & -0.39 \\
\hline Blood loss (mL) & $-1243 *$ & $-1285 *$ & $-1216 *$ & $-1306 *$ & $-1413 *$ & $-1178 *$ & $-1629 *$ & $-2261 *$ \\
\hline Intensive care (days) & -4.81 & -2.24 & $-2.12 *$ & -2.32 & -2.07 & -2.22 & $-0.80 *$ & $-1.94 *$ \\
\hline Length of stay (days) & $-5.55 *$ & $-5.54 *$ & $-5.79 *$ & $-5.36 *$ & $-5.97 *$ & $-4.93 *$ & $-12.30 *$ & $-6.80 *$ \\
\hline
\end{tabular}

Notes: *statistically significant: $\mathrm{p}$-value $<0.05$. Both WMD and odds ratio were calculated with patient weights.

Abbreviations: WMD, weighted mean difference; EVAR-OSR, odds ratio (EVAR/OSR).

In addition, when the trends in the difference in perioperative mortality were determined against the mid-enrolment time of the study, there was a small but statistically significant difference that persisted over time. The mortality difference has been changing at a rate of $0.066 \%$ per year $(\mathrm{P}<0.001)$.

\section{Mid-term mortality}

No statistical difference in mid-term mortality was found between EVAR and OSR over time. This evidence was based on a total of 6,289 patients with EVAR and 3,547 who received OSR and were followed in comparative nRCT up to a maximum of 36 months. In RCTs, 914 patients received EVAR, and 784 patients received OSR with a mean follow-up of 28 months of follow-up (table not provided).

\section{Discussion}

In the question of EVAR versus OSR, the RCT evidence is limited. The enrolment period for DREAM was November
2000 to December 2003, and for EVAR 1 enrolment periods were September 1999 to December 2003. Based on this work and earlier work (Franks et al 2007), this RCT evidence may be dated. Future evidence may come from an ongoing large multi-center trial, The Open Versus Endovascular Repair (OVER) Trial for Abdominal Aortic Aneurysms, which had an enrolment period, beginning in 2001 and ending in 2010. The recruitment period will be more up-to-date and thus, based on the results from this analysis, we should expect lower perioperative mortality rates in both EVAR and OSR, but similar mortality differences, as well as lower rates of endoleaks and ischemia. In the absence of more RCTs, observational data may provide the only current evidence.

There are some differences in evidence in nRCTs and RCTs. There are baseline imbalances that exist in nRCTs. In nRCTS, lower rates of outcomes are reported for all measures except limb ischemia which is higher in EVAR. A recent report has identified that there are only small differences

Table 4 Local/vascular complications

\begin{tabular}{|c|c|c|c|c|c|c|c|c|}
\hline \multirow[t]{4}{*}{ Studies } & RCT & $\mathrm{nRCT}$ & Multi-center & Single center & Low volume & High volume & Suitable & High risk \\
\hline & Odds & Odds & Odds & Odds & Odds & Odds & Odds & Odds \\
\hline & ratio & ratio & ratio & ratio & ratio & ratio & ratio & ratio \\
\hline & 4 & 75 & 16 & 59 & 31 & 28 & 5 & 8 \\
\hline Graft infection & 0.506 & 4.646 & - & 3.518 & - & 2.458 & - & - \\
\hline Graft thrombosis & - & $3.088 *$ & 2.242 & $2.98 I$ & - & $3.05 I *$ & - & - \\
\hline Aortenteric fistula & - & - & - & - & - & - & - & - \\
\hline Arterial/graft obstruction & - & 2.853* & - & $2.890 *$ & 1.566 & $8.952 *$ & 2.635 & - \\
\hline Groin minor & - & 2.869* & - & $3.035 *$ & $3.777 *$ & 1.735 & 2.269 & - \\
\hline Groin/wound infection & - & 0.871 & $0.49 I^{*}$ & 1.197 & $2.16 *$ & 0.977 & 0.738 & - \\
\hline Hemorrhage - major & $0.165 *$ & $0.297^{*}$ & $0.25 I^{*}$ & $0.288 *$ & $0.305 *$ & $0.269 *$ & $\mathrm{I} .747$ & - \\
\hline Hemorrhage - moderate & - & $0.421 *$ & - & $0.421 *$ & $0.344 *$ & 0.577 & - & $0.177 *$ \\
\hline Pseudoaneurysm - abdominal & - & $0.151 *$ & - & 0.209 & - & - & - & - \\
\hline Thromboembolism - major & 2.047 & $0.229 *$ & - & $0.249 *$ & 0.521 & $0.203 *$ & - & - \\
\hline Thromboembolism - moderate & - & $2.435 *$ & - & $2.297 *$ & 1.613 & $7.200 *$ & - & - \\
\hline Wound major & 1.018 & 0.570 & $0.380 *$ & 0.230 & - & 0.232 & - & - \\
\hline
\end{tabular}

Notes: *statistically significant: $\mathrm{p}$-value $<0.05$. Both WMD and odds ratio were calculated with patient weights. Abbreviations: WMD, weighted mean difference; EVAR-OSR, odds ratio (EVAR/OSR). 
Table 5 EVAR outcomes

\begin{tabular}{lllllllll}
\hline & $\mathbf{R C T}$ & $\mathbf{n R C T}$ & Multi-center & Single center & Low volume & High volume & Suitable & High risk \\
Studies & $\mathbf{4}$ & $\mathbf{7 5}$ & $\mathbf{1 6}$ & $\mathbf{5 9}$ & $\mathbf{3 1}$ & $\mathbf{2 8}$ & $\mathbf{5}$ & $\mathbf{8}$ \\
\hline Endoleaks & $\%$ & $\%$ & $\%$ & $\%$ & $\%$ & $\%$ & $\%$ & $\%$ \\
typel & 0 & 6.27 & 4.37 & 7.89 & 8.47 & $7.5 \mathrm{I}$ & 15.00 & 2.22 \\
type2 & 5.0 & 10.57 & 8.47 & 12.11 & 13.51 & 11.4 & 5.00 & 26.67 \\
type3 & 0 & 0.69 & 0.67 & 0.72 & 0.60 & 0.79 & 0 & 1.11 \\
type4 & 0 & 1.07 & 2.14 & 0 & 0 & 0 & 0 & 0 \\
Conversion & I.8I & 1.49 & 1.95 & 0.98 & 1.09 & 0.94 & 0.38 & 0.36 \\
Graft obstruction & n.a. & 1.08 & 0 & 1.59 & 5.58 & 0 & 14.46 & 0 \\
Graft kinks or folds & n.a. & 0.53 & 0.64 & 0.45 & 1.35 & 0 & 0 & 0 \\
Graft migration & n.a. & 0.61 & 0.35 & 0.86 & 2.02 & 0.17 & 0 & 8.33 \\
\hline
\end{tabular}

between one large registry (Eurostar) and one large RCT (DREAM) (Leurs et al 2007).

There are a number of large multi-center studies, including the Eurostar registry, Lifeline Registry for post device trial outcomes, and the large multi-center device trials. Also present are state, veteran affairs, and US national registries. In this study, care was taken to exclude the single center studies that make up the device trial evidence. There are some baseline differences between the multi-center and single center evidence. However, outcomes are mostly similar; the exceptions being that endoleaks (type 1 and type 2 endoleaks) are reportedly higher in single center studies.

The difference between low and high volume centers have been reported for other cardiac procedures (Narayan et al 2004) and for AAA repair (Bush et al 2006). In this report, there were no differences in baseline differences in AAA diameter or age, and slightly more ASA IV patients in EVAR in low volume centers. Balancing this is that high volume centers had more patients receiving EVAR with smoking history, hyperlipidemia and other comorbidities. This translates into similar outcomes in low volume and high

Table 6 Endoleaks and limb ischemia

\begin{tabular}{cll}
\hline Outcome & $\begin{array}{l}\text { Meta-analysis \% } \\
(\mathbf{9 5 \%} \mathbf{C l})\end{array}$ & $\begin{array}{l}\text { Meta-regression } \\
\text { trend \% (P-value) }\end{array}$ \\
\hline Endoleak & & \\
Type I & $6.77 \%(3.26 \%$ to $10.27 \%)$ & $-0.76 \%(\mathrm{P}=0.39)$ \\
Type 2 & $9.78 \%(6.76 \%$ to $12.79 \%)$ & $-0.47 \%(\mathrm{P}=0.59) *$ \\
Type 3 & $0.68 \%(0.43 \%$ to $0.94 \%)$ & $+0.17 \%(\mathrm{P}=0.0 \mathrm{I})$ \\
Type 4 & $0.33 \%(0.12 \%$ to $0.54 \%)$ & $-0.22 \%(\mathrm{P}<0.0 \mathrm{I})$ \\
Limb ischemia & $0.95 \%(0.94 \%$ to $0.96 \%)$ & $-0.02 \%(\mathrm{P}<0.0 \mathrm{I})$ \\
(EVAR-OSR) & & \\
\hline
\end{tabular}

Notes: Coefficient on time trend in meta-regression; *: one outlier with $100 \%$ rate of Type 2 Endoleak was removed from analysis. volume centers, with the exception of chronic renal failure being higher in EVAR for high volume centers.

Studies that have patients, who are suitable for both EVAR and OSR should have results similar to RCTs because of similar anatomical suitability. Collectively, the total number of these patients is the same as an RCT (larger than DREAM, smaller than EVAR 1). Mortality difference and cardiac, pulmonary and renal outcomes are similar to the RCTs. One key difference is the total length of hospital stay, which is much higher in EVAR in the nRCT suitable patients. This suggests that the differences in ASA III or IV lead to differences in OR times, ICU stay and hospital stay.

The RCTs and most nRCTs have a mixed population, with high risk and low risk patients. In this report, 8 studies that looked exclusively at high-risk patients were identified, These high risk patients incurred a lower rate of cardiac and pulmonary problems in EVAR than OSR. This suggests a significant benefit for high risk patients in terms of reduced systemic outcomes even when they are at a higher relative risk.

Long term data was analyzed to compare EVAR versus OSR for long term mortality. No statistical difference was found for up to 36 months. Almost all recent evidence has reported no significant difference in long term mortality (Drury et al 2005; Ho et al 2006). Differences that existed earlier (Walschot et al 2002) no longer exist.

Outcomes reported for EVAR have been improving over time and there are a number of reasons for this. First, there has been improvements in outcomes for EVAR surgical procedures through an evolving experience curve (Forbes et al 2004) preselecting suitable patients that would benefit from EVAR, or adjusting the device and perioperative adjuvant procedures to reduce later complications such as endoleaks and limb ischemia. Second, there have been improvements in the EVAR device almost eliminating type 3 or 4 
endoleaks (device failures). Third, there has been an increased tendency to have lower risk patients receive EVAR (Anderson et al 2004). In comparison, other studies have reported improving outcomes for patients that receive OSR (Black and Cambria 2006). This is the first study that demonstrates that the mortality risk difference is only slightly falling with time. This is supported by earlier comparative meta-analysis and recent comparative meta-analysis.

EVAR highlights the problem of performing a fixed point in time meta-analysis of a procedure that is continually evolving and technologically improving over time.

\section{Disclosure}

The authors report no conflicts of interest in this work.

\section{References}

Aarts F, van Sterkenburg S, Blankensteijn JD. 2005. Endovascular aneurysm repair versus open aneurysm repair: comparison of treatment outcome and procedure-related reintervention rate. Ann Vasc Surg, 19:699-704.

Aho PS, Niemi T, Lindgren L, et al. 2004. Endovascular vs open AAA repair: Similar effects on renal proximal tubular function. Scand $J$ Surg, 93:52-6.

Akkersdijk GJM, Prinssen M, Blankensteijn JD. 2004. The impact of endovascular treatment on in-hospital mortality following non-ruptured AAA repair over a decade: A population based study of 16,446 patients. Eur $J$ Vasc Endovasc Surg, 28:41-6.

Anderson PL, Arons RR, Moskowitz AJ, et al. 2004. A statewide experience with endovascular abdominal aortic aneurysm repair: Rapid diffusion with excellent early results. J Vasc Surg, 39:10-9.

Angle N, Dorafshar AH, Moore WS, et al. 2004. Open versus endovascular repair of abdominal aortic aneurysms: What does each really cost? Ann Vasc Surg, 18:612-18.

Arko FR, Hill BB, Reeves TR, et al. 2003. Early and late functional outcome assessments following endovascular and open aneurysm repair. $J$ Endovasc Ther, 10:2-9.

Ballard JL, Abou-Zamzam AM, Teruya TH, et al. 2004. Quality of life before and after endovascular and retroperitoneal abdominal aortic aneurysm repair. J Vasc Surg, 39:797-803.

Baxendale BR, Baker DM, Hutchinson A, et al. 1996. Haemodynamic and metabolic response to endovascular repair of infra-renal aortic aneurysms. Br J Anaesth, 77:581-5.

Becquemin JP, Bourriez A, d'Audiffret A, et al. 2000. Mid-term results of endovascular versus open repair for abdominal aortic aneurysm in patients anatomically suitable for endovascular repair. Eur J Vasc Endovasc Surg, 19:656-61.

Beebe HG, Cronenwett JL, Katzen BT, et al. 2001. Results of an aortic endograft trial: Impact of device failure beyond 12 months. $J$ Vasc Surg, 33:S55-S64.

Berman SS, Genrile AT, Berens ES, et al. 2002. Institutional economic losses associated with AAA repair are independent of technique. $J$ Endovasc Ther, 9:282-8.

Bertrand M, Godet G, Koskas F, et al. 2001. Endovascular treatment of abdominal aortic aneurysms: Is there a benefit regarding postoperative outcome? Eur J Anaesthesiol, 18:245-50.

Birch SE, Stary DR, Scott AR. 2000. Cost of endovascular versus open surgical repair of abdominal aortic aneurysms. Aust $N$ Z J Surg, 70:660-6.

Black JH III, Cambria RP. 2006. Current results of open surgical repair of descending thoracic aortic aneurysms. J Vasc Surg, 43(Suppl): $6 \mathrm{~A}-11 \mathrm{~A}$.
Blankensteijn JD, de Jong SE, Prinssen M, et al; Dutch Randomized Endovascular Aneurysm Management (DREAM) Trial Group. 2005. Twoyear outcomes after conventional or endovascular repair of abdominal aortic aneurysms. N Engl J Med, 352:2398-405.

Borchard KL, Birch SE, Hewitt PM, et al. 2005. Endovascular abdominal aortic aneurysm repair: a 7 year experience at the Launceston General Hospital. Aust N Z J Surg, 75:302-7.

Bren L. 2003. Company caught in coverup of medical devices. FDA Consumer Magazine, Nov - Dec, pp. 1-2.

Brewster DC, Geller SC, Kaufman JA, et al. 1998. Initial experience with endovascular aneurysm repair: Comparison of early results with outcome of conventional open repair. J Vasc Surg, 27:992-1005.

Bush RL, Johnson ML, Collins TC, et al. 2006a. Open versus endovascular abdominal aortic aneurysm repair in VA hospitals. J Am Coll Surg, 202:577-87.

Buth J, Parodi J. 1999. EUROSTAR update. Round Table Series - Royal Society of Medicine, pp. 13-8.

Cao P, Verzini F, Parlani G, et al. 2004. Clinical effect of abdominal aortic aneurysm endografting: 7-year concurrent comparison with open repair. J Vasc Surg, 40:841-8.

Carpenter JP. 2006. The Powerlink bifurcated system for endovascular aortic aneurysm repair: four-year results of the US multicenter trial. $J$ Cardiovasc Surg, 47:239-43.

Carpenter JP, Baum RA, Barker CF, et al. 2002. Durability of benefits of endovascular versus conventional abdominal aortic aneurysm repair. $J$ Vasc Surg, 35:222-8.

Carpenter JP, Endologix I. 2004. Midterm results of the multicenter trial of the powerlink bifurcated system for endovascular aortic aneurysm repair. J Vasc Surg, 40:849-59.

Ceelen W, Sonneville T, Randon C, et al. 1999. Cost-benefit analysis of endovascular versus open abdominal aortic aneurysm treatment. Acta Chirurgica Belgica, 99:64-7.

Chaikof EL, Blankensteijn JD, Harris PL, et al. Ad Hoc Committee for Standardized Reporting Practices in Vascular Surgery of The Society for Vascular Surgery/American Association for Vascular Surgery 2002. Reporting standards for endovascular aortic aneurysm repair. $J$ Vasc Surg, 35:1048-60.

Clair DG, Gray B, O’Hara PJ, et al. 2000. An evaluation of the costs to health care institutions of endovascular aortic aneurysm repair. $J$ Vasc Surg, 32:148-52.

Cohnert TU, Oelert F, Wahlers T, et al. 2000. Matched-pair analysis of conventional versus endoluminal AAA treatment outcomes during the initial phase of an aortic endografting. J Endovasc Ther, 7:94-100.

Criado FJ, Fairman RM, Becker GJ. 2003. Talent LPS AAA stent graft: Results of a pivotal clinical trial. J Vasc Surg, 37:709-15.

Cuypers PW, Gardien M, Buth J, et al. 2001. Randomized study comparing cardiac response in endovascular and open abdominal aortic aneurysm repair. Br J Surg, 88:1059-65.

Davies MJ, Arhanghelschi I, Grauer R, et al. 2002. Anaesthesia for endoluminal repair of abdominal aortic aneurysms. Anaesth Intensive Care, 30:66-70.

de Donato G, Chisci E, Trovato R, et al. 2006. Open and endovascular treatment of abdominal aortic aneurysm in octogenarians: A single center approach. Italian J Vasc Endovasc Surg, 13:77-81.

de Virgilio C, Bui H, Donayre C, et al. 1999. Endovascular vs open abdominal aortic aneurysm repair: A comparison of cardiac morbidity and mortality. Arch Surg, 134:947-51.

Decker D, Springer W, Decker P, et al. 2003. Changes in TH1/TH2 immunity after endovascular and conventional infrarenal aortic aneurysm repair: Its relevance for clinical practice. Eur J Vasc Endovasc Surg, 25:254-61.

Dias NV, Ivancev K, Malina M, et al. 2003. Does the wide application of endovascular AAA repair affect the results of open surgery? Eur J Vasc Endovasc Surg, 26:188-94.

Drury D, Michaels JA, Jones L, et al. 2005. Systematic review of recent evidence for the safety and efficacy of elective endovascular repair in the management of infrarenal abdominal aortic aneurysm. Br J Surg, 8:937-46. 
Dryjski M, O’Brien-Irr MS, Hassett J. 2003. Hospital costs for endovascular and open repair of abdominal aortic aneurysm. J Am Coll Surg, 197:64-70.

Du Toit DF, Saaiman A, De Beer R, et al. 1998. Endovascular stent-graft repair of abdominal aortic aneurysms - Single- center experience and acute outcome. Cardiovasc J S Afr, 88:C273-C81.

Elkouri S, Gloviczki P, McKusick MA, et al. 2004. Perioperative complications and early outcome after endovascular and open surgical repair of abdominal aortic aneurysms. J Vasc Surg, 39:497-505.

Englberger L, Savolainen H, Jandus P, et al. 2006. Activated coagulation during open and endovascular abdominal aortic aneurysm repair. J Vasc Surg, 43:1124-9.

Forbes TL, DeRose G, Kribs S, et al. 2002. A cost-effectiveness analysis of standard versus endovascular abdominal aortic aneurysm repair. Can $J$ Surg, 45:420-4.

Forbes TL, DeRose G, Kribs SW, et al. 2004. Cumulative sum failure analysis of the learning curve with endovascular abdominal aortic aneurysm repair. J Vasc Surg, 39:102-8.

Forbes TL, Lawlor DK, DeRose G, et al. 2005. National audit of the recent utilization of endovascular abdominal aortic aneurysm repair in Canada: 2003 to 2004. J Vasc Surg, 42:410-4.

Franks SC, Sutton AJ, Bown MJ, et al. 2007. Systematic review and metaanalysis of 12 years of endovascular abdominal aortic aneurysm repair. Eur J Vasc Endovasc Surg, 2:154-71.

Galle C, De Maertelaer V, Motte S, et al. 2000. Early inflammatory response after elective abdominal aortic aneurysm repair: A comparison between endovascular procedure and conventional surgery. $J$ Vasc Surg, 32:234-46.

Garcia-Madrid C, Josa M, Riambau V, et al. 2004. Endovascular versus open surgical repair of abdominal aortic aneurysm: A comparison of early and intermediate results in patients suitable for both techniques. Eur J Vasc Endovasc Surg, 28:365-72.

Gawenda M, Zaehringer M, Brunkwall J. 2003. Open versus endovascular repair of para-anastomotic aneurysms in patients who were morphological candidates for endovascular treatment. J Endovasc Ther $10: 745-51$.

Goueffic Y, Becquemin J-P, Desgranges P, et al. 2005. Midterm survival after endovascular versus open repair of infrarenal aortic aneurysms $J$ Endovasc Ther, 12:47-57.

Greenberg RK, Chuter TAM, Sternbergh III WC, et al. 2004. Zenith AAA endovascular graft: Intermediate-term results of the US multicenter trial. J Vasc Surg, 39:1209-18.

Greenhalgh RM. 2005. Endovascular aneurysm repair versus open repair in patients with abdominal aortic aneurym (EVAR trial 1): Randomised controlled trial. Lancet, 365:2179.

Greenhalgh RM, Brown LC, Kwong GP, et al. 2004. Comparison of endovascular aneurysm repair with open repair in patients with abdominal aortic aneurysm (EVAR trial 1), 30-day operative mortality results: Randomised controlled trial. Lancet, 364:843-8.

Hansman MF, Neuzil D, Quigley TM, et al. 2003. A comparison of 50 initial endoluminal endograft repairs for abdominal aortic aneurysm with 50 concurrent open repairs. Am J Surg, 185:441-4.

Hayter CL, Bradshaw SR, Allen RJ, et al. 2005. Follow-up costs increase the cost disparity between endovascular and open abdominal aortic aneurysm repair. J Vasc Surg, 42:912-18.

Ho P, Yiu WK, Cheung GC, et al. 2006. Systematic review of clinical trials comparing open and endovascular treatment of abdominal aortic aneurysm. Surg Pract, 1:24-37.

Hollier LH, Taylor LM, Ochsner J. 1992. Recommended indications for operative treatment of abdominal aortic aneurysms. Report of a subcommittee of the Joint Council of the Society for Vascular Surgery and the North American Chapter of the International Society for Cardiovascular Surgery. J Vasc Surg, 15:1046-56.

Hua HT, Cambria RP, Chuang SK, et al. 2005. Early outcomes of endovascular versus open abdominal aortic aneurysm repair in the National Surgical Quality Improvement Program-Private Sector (NSQIP-PS). J Vasc Surg, 41:382-9.
Iannelli G, Monaco M, Di Tommaso L, et al. 2005. Endovascular vs. open surgery of abdominal aortic aneurysm in high-risk patients: a single center experience. Thorac Cardiovasc Surg, 53:291-4.

Jordan WD, Alcocer F, Wirthlin DJ, et al. 2003. Abdominal aortic aneurysms in 'high-risk' surgical patients: Comparison of open and endovascular repair. Ann Surg, 237:623-30.

Junnarkar S, Lau LL, Edrees WK, et al. 2003. Cytokine activation and intestinal mucosal and renal dysfunction are reduced in endovascular AAA repair compared to surgery. $J$ Endovasc Ther, 10:195-202.

Kahn RA, Moskowitz DM, Manspeizer HE, et al. 1999. Endovascular aortic repair is associated with greater hemodynamic stability compared with open aortic reconstruction. J Cardiothorac Vasc Anesth, 13:42-6.

Kibbe MR, Matsumura JS. 2003. The Gore Excluder US Multi-Center Trial: Analysis of adverse events at 2 years. Semin Vasc Surg, 16:144-50.

Leon LR Jr, Labropoulos N, Laredo J, et al. 2005. To what extent has endovascular aneurysm repair influenced abdominal aortic aneurysm management in the state of Illinois? J Vasc Surg, 41:568-74.

Leurs LJ, Buth J, Harris PL, et al. 2007. Impact of study design on outcome after endovascular abdominal aortic aneurysm repair. A comparison between the randomized controlled DREAM-trial and the observational EUROSTAR-registry. Eur J Vasc Endovasc Surg, 33:172-6.

[LREAR] Lifeline Registry of Endovascular Aneurysm Repair Steering Committee. 2001. Lifeline Registry: collaborative evaluation of endovascular aneurysm repair. J Vasc Surg, 34:1139-46.

[LREAR] Lifeline Registry of EVAR Publications Committee. 2005. Lifeline registry of endovascular aneurysm repair: long-term primary outcome measures. J Vasc Surg, 42:1-10.

Ligush JJ, Pearce JD, Edwards MS, et al. 2002. Analysis of medical risk factors and outcomes in patients undergoing open versus endovascular abdominal aortic aneurysm repair. J Vasc Surg, 36:492-9.

Makaroun MS, Chaikof E, Naslund T, et al. 2002. Efficacy of a bifurcated endograft versus open repair of abdominal aortic aneurysms: a reappraisal. J Vasc Surg, 35:203-10.

Malina M, Nilsson M, Brunkwall J, et al. 2000. Quality of life before and after endovascular and open repair of asymptomatic AAAs: A prospective study. J Endovasc Ther, 7:372-9.

Manis G, Feuerman M, Hines GL. 2006. Open aneurysm repair in elderly patients not candidates for endovascular repair (EVAR): Comparison with patients undergoing EVAR or preferential open repair. Vasc Endovasc Surg, 40:95-101.

Matsumura JS, Brewster DC, Makaroun MS, et al. 2003. A multicenter controlled clinical trial of open versus endovascular treatment of abdominal aortic aneurysm. J Vasc Surg, 37:262-71.

May J, White GH, Waugh R, et al. 2001. Improved survival after endoluminal repair with second-generation prostheses compared with open repair in the treatment of abdominal aortic aneurysms: A 5-year concurrent comparison using life table method. J Vasc Surg, 33(2 Suppl):S21-S6.

Mehta M, Roddy SP, Darling III RC, et al. 2005. Infrarenal abdominal aortic aneurysm repair via endovascular versus open retroperitoneal approach. Ann Vasc Surg, 19:374-8.

Mendonca CT, Moreira RCR, Ribas T Jr, et al. 2005. Comparison between open and endovascular treatment of abdominal aortic aneurysms in high surgical risk patients. Journal Vascular Brasileiro, 4:232-42.

Moise MA, Woo EY, Velazquez OC, et al. 2006. Barriers to endovascular aortic aneurysm repair: past experience and implications for future device development. Vasc Endovasc Surg, 40:197-203.

Moore WS, Brewster DC, Bernhard VM. 2001. Aorto-uni-iliac endograft for complex aortoiliac aneurysms compared with tube/bifurcation endografts: Results of the EVT/Guidant trials. J Vasc Surg, 33(Part 2):11-20.

Narayan P, Caputo M, Rogers CA, et al. 2004. Early and mid-term outcomes of surgery of the ascending aorta/arch: is there a relationship with caseload? Eur J Cardiothorac Surg, 25:676-82.

Odegard A, Lundbom J, Myhre HO, et al. 2000. The inflammatory response following treatment of abdominal aortic aneurysms: A comparison between open surgery and endovascular repair. Eur J Vasc Endovasc Surg, 19:536-44. 
Park B, Danes S, Drezner AD, et al. 2006. Endovascular abdominal aortic aneurysm repair at Hartford Hospital: A six year experience. Conn Med, 70:357-62.

Parmer SS, Fairman RM, Karmacharya J, et al. 2006. A comparison of renal function between open and endovascular aneurysm repair in patients with baseline chronic renal insufficiency. J Vasc Surg, 44:706-11.

Parodi JC, Palmaz JC, Barone HD. 1991. Transfemoral intraluminal graft implantation for abdominal aortic aneurysms. Ann Vasc Surg, 5:491-9.

Patel AP, Langan EM III, Taylor SM, et al. 2003. An analysis of standard open and endovascular surgical repair of abdominal aortic aneurysms in octogenarians. Am Surg, 69:744-7.

Prault TL, Stevens SL, Freeman MB, et al. 2004. Open versus endo: Early experience with endovascular abdominal aortic aneurysm repair beyond the clinical trials. Heart Surg Forum, 7:E459-61.

Prinssen M, Verhoeven EL, Buth J, et al. 2004. A randomized trial comparing conventional and endovascular repair of abdominal aortic aneurysms. N Engl J Med, 351:1607-18.

Rosenberg BL, Comstock MC, Butz DA, et al. 2005. Endovascular abdominal aortic aneurysm repair is more profitable than open repair based on contribution margin per day. Surgery, 137:285-92.

Rowlands TE, Homer-Vanniasinkam S. 2001. Pro- and anti-inflammatory cytokine release in open versus endovascular repair of abdominal aortic aneurysm. Br J Surg, 88:1335-40.

Sandridge LC, Baglioni AJ Jr, Kongable GL, et al. 2006. Evaluation of the effect of endovascular options on infrarenal abdominal aortic aneurysm repair. Am Surg, 72:700-4.

Sangiorgi G, D'Averio R, Mauriello A, et al. 2001. Plasma levels of metalloproteinases-3 and -9 as markers of successful abdominal aortic aneurysm exclusion after endovascular graft treatment. Circulation, 104(12 Suppl):i288-i95.

Sbarigia E, Speziale F, Ducasse E, et al. 2005. What is the best management for abdominal aortic aneurysm in patients at high surgical risk? A single-center review. Int Angiol, 24:70-4.

Scharrer-Pamler R, Kapfer X, Orend KH, et al. 1999. Endoluminal grafting of infrarenal aortic aneurysms. Thorac Cardiovasc Surg, 47:119-21.

Seiwert AJ, Wolfe J, Whalen RC, et al. 1999. Cost comparison of aortic aneurysm endograft exclusion versus open surgical repair. Am J Surg, 178:117-20.

Sicard GA, Rubin BG, Sanchez LA, et al. 2001. Endoluminal graft repair for abdominal aortic aneurysms in high-risk patients and octogenarians: Is it better than open repair? Ann Surg, 234:427-37.
Soulez G, Therasse E, Monfared AA, et al. 2005. Pain and quality of life assessment after endovascular versus open repair of abdominal aortic aneurysms in patients at low risk. $J$ Vasc Interv Radiol, 16:1093-100.

Teufelsbauer H, Prusa AM, Wolff K, et al. 2002. Endovascular stent grafting versus open surgical operation in patients with infrarenal aortic aneurysms: A propensity score-adjusted analysis. Circulation, 106:782-7.

Ting ACW, Cheng SWK, Ho P. 2003. Endovascular repair for abdominal aortic aneurysms: Initial experience of an endograft programme. Asian J Surg, 26:17-21.

Treharne GD, Thompson MM, Whiteley MS, et al. 1999. Physiological comparison of open and endovascular aneurysm repair. Br J Surg, $86: 760-4$.

Turnipseed W, Tefera G, Carr S. 2003. Comparison of minimal incision aortic surgery with endovascular aortic repair. Am J Surg, 186:287-91.

Van Sambeek MRHM, van Dijk LC, Hendriks JM, et al. 2002. Endovascular versus conventional open repair of acute abdominal aortic aneurysm: Feasibility and preliminary results. $J$ Endovasc Ther, 9:443-8.

Vogel TR, Nackman GB, Crowley JG, et al. 2005. Factors impacting functional health and resource utilization following abdominal aortic aneurysm repair by open and endovascular techniques. Ann Vasc Surg, 19:641-7.

Wald R, Waikar SS, Liangos O, et al. 2006. Acute renal failure after endovascular vs open repair of abdominal aortic aneurysm. J Vasc Surg, 43:460-6.

Walschot LHB, Laheij RJF, Verbeek ALM. 2002. Outcome after endovascular abdominal aortic aneurysm repair: A meta-analysis. $J$ Endovasc Ther, 9:82-9.

Watson DR, Tan J, Wiseman L, et al. 2004. Challenges associated with the integration of endovascular repair of abdominal aortic aneurysms in a community hospital. Heart Surg Forum, 7:E508-E13.

Welborn MB III, Yau FS, Modrall JG, et al. 2005. Endovascular repair of small abdominal aortic aneurysms: A paradigm shift? Vasc Endovasc Surg, 39:381-91.

Wijnen MH, Cuypers P, Buth J, et al. 2001. Differences in renal response between endovascular and open repair of abdominal aortic aneurysms. Eur J Vasc Endovasc Surg, 21:171-4.

Zarins CK, White RA, Schwarten D, et al. 1999. Aneurx stent graft versus open surgical repair of abdominal aortic aneurysms: Multicenter prospective clinical trial. J Vasc Surg, 29:292-308.

Zeebregts CJ, Geelkerken RH, van der Palen J, et al. 2004. Outcome of abdominal aortic aneurysm repair in the era of endovascular treatment. Br J Surg, 91:563-8. 